\title{
Evacuation Support System for Everyday Use in the Aftermath of a Natural Disaster
}

\author{
Akari Hamamura ${ }^{1}$, Taku Fukushima ${ }^{2}$, Takashi Yoshino ${ }^{1}$, and Nobuyuki Egusa ${ }^{1}$ \\ 1 Faculty of Systems Engineering, Wakayama University \\ $\{$ s155037, yoshino, egusa\}@center. wakayama-u.ac.jp \\ 2 Graduate School of Engineering, Shizuoka University \\ fukushima@sys.eng.shizuoka.ac.jp
}

\begin{abstract}
Numerous natural disasters occur in Japan, such as earthquakes, typhoons, and volcanic eruptions. Information technology is expected to facilitate evacuation support when a disaster strikes, but networks cannot be used in many cases. Moreover, if a disaster occurs in a town that people do not frequent often, they may find it difficult to cope initially. It is difficult to access software online immediately at the time of a disaster. Thus, we have developed an evacuation support system called AkariMap, which can be used offline in the aftermath of a disaster. AkariMap is also a system that is suitable for everyday use. AkariMap has two functions: a function that notifies a user about evacuation support information each day and a disaster mode function that users can access at times of emergency. Based on the results of our experiments, we report the following findings. (1) Subjects increasingly accessed local evacuation support information for about 10 days. (2) Even if people did not use the notification function in the long-term, they were still accustomed to using the system. (3) If people need to find a shelter using AkariMap, they can identify a safer shelter by displaying the flooded areas.
\end{abstract}

Keywords: disaster system, evacuation support, everyday use, offline support system.

\section{Introduction}

The communication networks required for information and communication technology were destroyed immediately after the Great East Japan Earthquake (GEJE) in 2011. However, networks and information technology are indispensable for information communication in a stricken area. For example, Google Person Finder [1] could be used to collect and provide information that supports the well-being of people in a disaster area.

To prepare for disasters that may occur in the future, many researchers and companies in Japan are addressing the potential problems associated with earthquakes, and they are developing new services to support the recovery from various disasters 2 . However, most of the studies and services that are being developed 
assume that a network will be available for use after a disaster. In reality, a network becomes crowded and congested immediately after a disaster occurs. Furthermore, the communication network may be physically disrupted and electric power outages may occur 3 .

During the GEJE, $79.6 \%$ of the evacuees had their mobile phones with them 4]. Thus, the majority of the evacuees recognized the necessity for a mobile phone. All of the mobile phones used in Japan are equipped with an emergency messaging service. However, the utilization rate of this service was only $4.5 \%$ during the GEJE [4, whereas the utilization rate before the GEJE was $6.5 \%$. Thus, we consider that it may be difficult to use this type of unfamiliar service immediately when an emergency occurs 4. Moreover, many people cannot obtain evacuation support information, such as a travel destination or business destination.

If a disaster occurs in a place where evacuation support information is not available, it is necessary to search for a shelter amid the confusion. Some people cannot cope with the conditions immediately and they may experience severe distress. Thus, we consider that a new system with two elements is required, as follows.

- It should be possible to use the system even if no network is available after a disaster occurs.

- It should be possible to acquire experience of the emergency function before a disaster occurs.

Thus, we have developed an evacuation support system called AkariMap [5], which has two functions: a function that provides a user with evacuation support information and a disaster mode function that a user can experience at any time. This study presents the detailed functions of AkariMap and the results of evaluation experiments.

\section{Related Work}

Fukuda et al. developed a tsunami evacuation support system based on a tablet PC [6], which can be used offline. This system uses an offline type GIS and it displays a tsunami hazard map, positional information, and the movements of a user. Hiruta et al. developed a disaster information sharing system to facilitate the search for a shelter after a disaster [7]. This system provides information collected by the evacuees regarding shelters and it allows disaster information sharing using smartphones. The system uses a smartphone as a server and the disaster information is accumulated by the smartphone. Therefore, if a communication base cannot be utilized during a disaster, this system can be used to share information about shelters. However, these systems were not designed for daily use.

Fujikawa et al. developed a disaster support system for everyday use that collects and shares disaster information 8. This system can be used in the same way as a typical SNS but it can also share information during disasters. The system switches into disaster mode during a disaster and exchanges disasterrelated information via an independent network. This system was designed for 


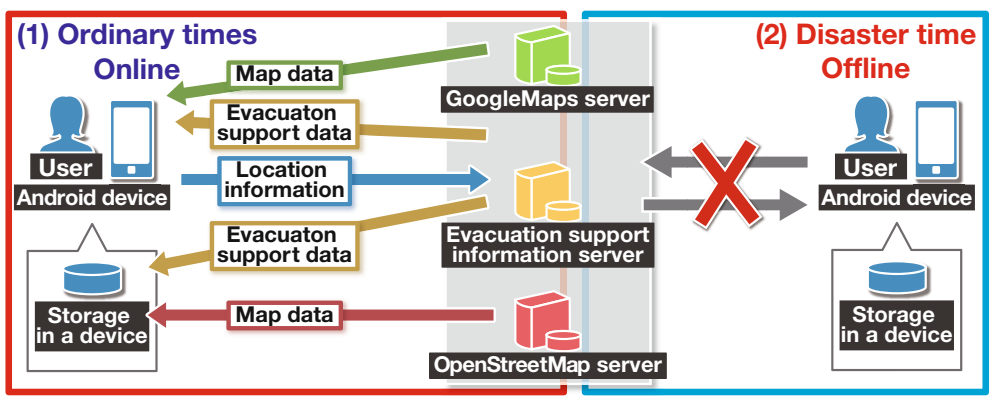

Fig. 1. System configuration for AkariMap

daily use, but no function is available that allows the continuous use of the system.

We consider that it may be difficult to use unfamiliar systems that are not used on a daily basis if a disaster occurs. Thus, we propose a notification function for continuous use and a disaster mode function that a user can test at any time.

\section{AkariMap}

We assume that online support should be available before a disaster strikes and that offline help needs to be provided immediately after a disaster. AkariMap is an evacuation support system for everyday use. AkariMap operates on an Android device. AkariMap offers online support via a map screen and a widget function.

A notification function provides support information during evacuations. One of the aims of the notification function is to promote the use of the system. AkariMap offers a disaster mode, which users can experience at any time.

AkariMap automatically saves the evacuation-related support information and map information to a mobile device in the online mode. The saved information can be used during a disaster (in the offline mode).

\subsection{System Configuration}

Figure 1 shows the system configuration for AkariMap. AkariMap comprises each user's android device, an evacuation support information server, GoogleMaps server, and OpenStreetMaps server 1 . The system is designed for use in both online (before a disaster strike) and offline (immediately after a disaster) modes. In an online situation, AkariMap obtains and saves positional information. Furthermore, the system provides a display and notifications of evacuation support information. In the offline mode, AkariMap offers evacuation support. In addition, AkariMap does not determine a destination automatically, because it can only suggest information. This is because a mobile device cannot acquire local information in the offline mode.

\footnotetext{
${ }^{1}$ Lhttp://www . openstreetmap.org/
} 


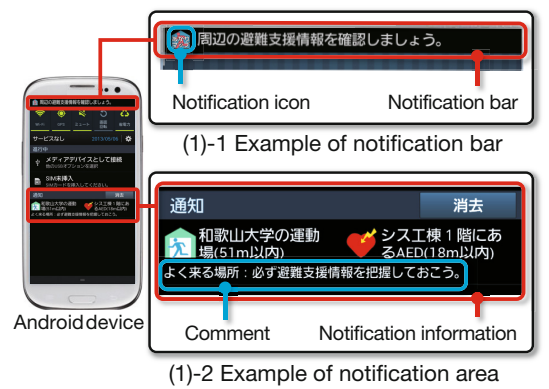

(1) Examples of notification
(2)-1 Battery level(Disaster mode)

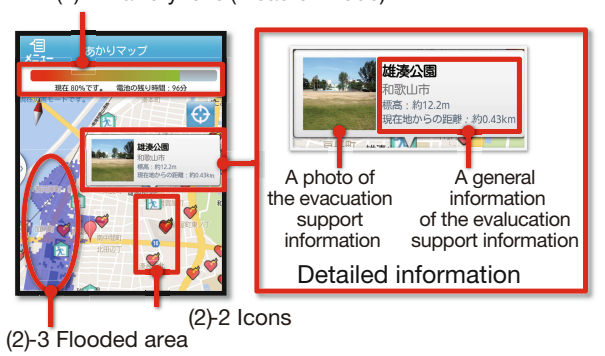

(2) Examples of map screen

Fig. 2. Examples showing a screenshot of AkariMap

\subsection{Functions of AkariMap}

Notification Function. Figure 2(1) shows an example of a notification screen. An Android device has two areas for notification: the notification bar and notification area. Figure 2(1)-1 shows an example of the notification bar and Figure 2(1)-2 shows an example of the notification area. The notification function provides evacuation support information to a user. For example, the notification bar suggests: "Let us check the local evacuation support information." The notification area presents notification comments and evacuation information. The evacuation information system suggests the nearest shelter and the nearest automatic external defibrillator (AED). AkariMap can be activated by tapping on the contents of a notification.

Disaster Mode Experience Function. In general, it is difficult to become accustomed to the use of unfamiliar software during an emergency. Thus, to facilitate the use of a beneficial function during a disaster, we developed the "disaster mode" for use at any time, thereby ensuring familiarity. A user can access the following functions in the disaster mode at any time before a disaster occurs: data cache function, remaining battery level function, map function, and widget function.

Data Cache Function. The data cache function acquires useful information offline before a disaster strikes. When a user is browsing the map screen, the system acquires evacuation support information and map data from OpenStreetMap are captured automatically as a background process 2 . A user can also acquire the data for a selected area. The acquired data is maintained in the internal storage of an Android device. Thus, evacuation support information can be provided to a user in the offline mode using the data stored before a disaster.

\footnotetext{
${ }^{2}$ GoogleMaps can be used as a map screen but the capture of map data is not allowed.

Thus, we also use OpenStreetMap in the offline mode.
} 
Remaining Battery Level Function. Figure 2(2)-1 shows an example of the remaining battery level function, which is used after a disaster occurs. This function allows a user to be aware of the remaining battery power. The function uses a notification dialog to display the battery power remaining in a smartphone and the predicted time remaining is shown on the screen. The notification dialog prompts the user to reduce the screen luminosity and to avoid the use of unnecessary applications. These two practices are also required for everyday use.

\subsection{Map Function}

The map function is available for online use before a disaster occurs. First, the function sends information about the user's present location to a server. Next, the function obtains evacuation support information related to the local area from a server and icons are displayed on a map. When a user taps the icon, detailed support information related to evacuation can be browsed, such as place names, photographs (if available), supplementary information, distances from the present location, and altitude. Figure 2(2)-3 shows a flooded area on a $\operatorname{man} 3$.

\subsection{Widget Function}

A widget is a small software application on an Android device, which is always displayed on the home (main) screen. The widget function can be used online before a disaster. Even if a user is at a destination, the widget function provides local evacuation support information periodically based on the user's present location. If a user does not activate the AkariMap application, the widget function can still make them aware of the evacuation support information. Thus, a user can be activated by the widget to access AkariMap.

\section{Experimental Evaluation of the Notification Function}

This experiment was conducted for 30 days between April 28 and May 27, 2013. The experimental participants comprised nine subjects, i.e., six male and three female, who were all university students. Each participant installed AkariMap in their personal Android device. We tested the following hypotheses.

(1) The notification function activates the user to access evacuation support information.

(2) The notification function triggers the use of the AkariMap system.

We preregistered the shelter and AED information for the area. We conducted three questionnaire-based surveys, i.e., before the experiment, on the 10th day of the experiment, and at the end of the experiment.

\footnotetext{
${ }^{3}$ In this case, the predicted flooded area is in Wakayama Prefecture, which is the local government in the study area.
} 
Table 1. Results of the questionnaire-based survey about the notification function at the end of the experiment (five-point Likert scale)

\begin{tabular}{|l|c|c|c|c|c|c|c|}
\hline question items & \multicolumn{3}{|c|}{ Distribution of the evaluations } & \multirow{2}{*}{ Median } & Mode \\
\cline { 2 - 7 } & 1 & 2 & 2 & 3 & 4 & 5 & \\
\hline $\begin{array}{l}\text { (1) The notification function activated you to obtain } \\
\text { evacuation support information related to your } \\
\text { frequent destination. }\end{array}$ & 0 & 1 & 3 & 5 & 0 & 4 & 4 \\
\hline $\begin{array}{l}\text { The notification function motivated you to use } \\
\text { AkariMap. }\end{array}$ & 0 & 0 & 0 & 7 & 2 & 4 & 4 \\
\hline
\end{tabular}

- We used a five-point Likert scale for the evaluation: 1: Strongly disagree, 2: Disagree, 3: Neutral, 4: Agree, and 5: Strongly agree.

- The distributions of the evaluation scores are shown for individual subjects.

Table 2. Increases in the number of evacuation support information acquisition events

\begin{tabular}{|c|c|c|}
\hline Participant & $\begin{array}{l}\text { From before the experiment until the } \\
\text { 10th day of the experiment }\end{array}$ & $\begin{array}{l}\text { From the 10th day of the experiment } \\
\text { until after the experiment }\end{array}$ \\
\hline A & 8 & 2 \\
B & 14 & 0 \\
C & 2 & 1 \\
D & 5 & 1 \\
E & 6 & 1 \\
F & 6 & 1 \\
G & 3 & 1 \\
H & 5 & 4 \\
I & 4 & 0 \\
\hline
\end{tabular}

Table 3. Number of system notifications and the number of system activations after a notification

\begin{tabular}{|c|c|c|c|c|}
\hline \multirow{2}{*}{\begin{tabular}{|l|} 
Participant \\
\end{tabular}} & \multicolumn{2}{|c|}{$\begin{array}{l}\text { From before the experiment until the } \\
10 \text { th day of the experiment }\end{array}$} & \multicolumn{2}{|c|}{$\begin{array}{l}\text { From the 10th day of the experiment un- } \\
\text { til the end of the experiment }\end{array}$} \\
\hline & $\begin{array}{l}\text { Number of notifica- } \\
\text { tions }\end{array}$ & \begin{tabular}{|l|} 
Number of system \\
activations after a \\
notification
\end{tabular} & $\begin{array}{l}\text { Number of notifica- } \\
\text { tions }\end{array}$ & \begin{tabular}{|l|l|} 
Number of system \\
activations after a \\
notification
\end{tabular} \\
\hline A & 5 & \begin{tabular}{|c|}
3 \\
\end{tabular} & 8 & 2 \\
\hline B & 7 & 2 & 15 & 0 \\
\hline $\mathrm{C}$ & 4 & 1 & 7 & 1 \\
\hline D & 7 & 1 & 11 & 1 \\
\hline $\mathrm{E}$ & 4 & 3 & 8 & 3 \\
\hline $\mathrm{F}$ & 10 & 1 & 19 & 0 \\
\hline G & 16 & 3 & 17 & 2 \\
\hline $\mathrm{H}$ & 20 & 5 & 30 & 8 \\
\hline I & 4 & 0 & 5 & 1 \\
\hline Average & 8.6 & 2.4 & 13.3 & 2.0 \\
\hline $\begin{array}{l}\text { Average system } \\
\text { activation rate }\end{array}$ & & & & \\
\hline
\end{tabular}

\subsection{Results of the Experimental Evaluation of the Notification Function and Discussion}

Table 1 shows the results of the questionnaire-based survey at the end of the experiment. We used a five-point Likert scale for the evaluation: 1: strongly disagree, 2: disagree, 3: neutral, 4: agree, and 5: strongly agree.

Awareness of Evacuation Support Information. Table 1(1) shows that for the question: "The notification function activated you to obtain evacuation support information related to your frequent destination," the median and mode 
scores were both 4 . In the free description field of the questionnaire-based survey, one participant commented: "The system displayed a shelter repeatedly in the notification, which I memorized without even noticing." Table 2 shows the increases in the number of evacuation support information acquisition events, which were calculated for two periods: from before the experiment until the 10th day of the experiment and from the 10th day of the experiment until after the end of the experiment. Table 2 shows that the number of evacuation support information acquisition events increased for all subjects on the 10th day compared with the number before the experiment. However, the number of evacuation support information acquisition events declined after the 10th day. Thus, we found that the long-term use of the notification function made users more aware of the evacuation support information. Moreover, we found that people continued to acquire increasing amounts of evacuation support information for 10 days.

Usage of AkariMap. Table11(2) shows that for the question: " the notification function motivated you to use AkariMap," the median and mode scores were both 4. The participants commented: "When the notification function was activated, I felt inclined to use it," and: "When the notification was displayed, I remembered the software and began to use it in many cases." Table 3 shows the increased in the average activation rate from before the experiment until the 10th day of the experiment, and from the 10th day of the experiment until the end of the experiment. Table 3 shows that the average activation rate declined from the 10th day of the experiment until after the end of the experiment. We consider that the participants became bored with the notification function after the 10th day. We suggest that many people found it difficult to continue using the same function for one month. We also found that some of the participants did not activate the system after this time. However, Table 3 shows that seven of the nine participants activated the system once or more between the 10th day and the end of the experiment. The average number of activations was about two. Although people used the notification function for long periods (about one month in the present study), we found that the function still activated them to use the system.

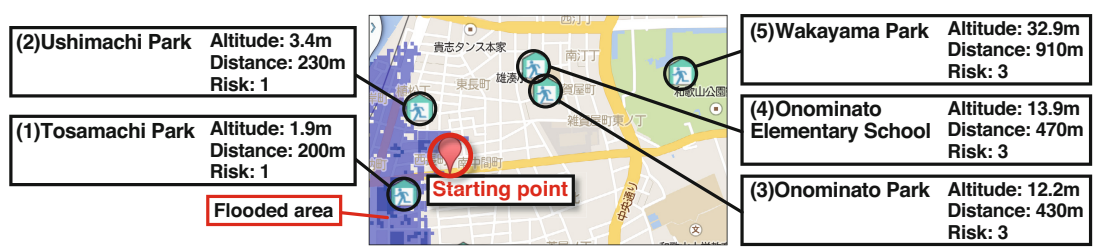

Fig. 3. Positions of the shelters around the test location 
Table 4. Shelter locations around the test site in detail

\begin{tabular}{|l|c|c|c|c|}
\hline & Name of shelter & Altitude & Distance & Risk level \\
\hline Shelter (1) & Tosamachi Park & $1.9 \mathrm{~m}$ & $200 \mathrm{~m}$ & 1 \\
\hline Shelter (2) & Ushimachi Park & $3.4 \mathrm{~m}$ & $230 \mathrm{~m}$ & 1 \\
\hline Shelter (3) & Onominato Park & $12.2 \mathrm{~m}$ & $430 \mathrm{~m}$ & 3 \\
\hline Shelter (4) & Onominato Elementary School & $13.9 \mathrm{~m}$ & $470 \mathrm{~m}$ & 3 \\
\hline Shelter (5) & Wakayama Park & $32.9 \mathrm{~m}$ & $910 \mathrm{~m}$ & 3 \\
\hline
\end{tabular}

\section{Experimental Evaluation in the Disaster Mode}

\subsection{Preliminary Experiment}

We also conducted a preliminary experimental evaluation of the disaster mode function 9]. In this experiment, we assumed that a major earthquake occurred. Each of five participants selected a shelter using the disaster mode function in AkariMap. In this experiment, AkariMap provide the following evacuation support information: the user's present location, the locations of shelters, the altitude of each shelter, and the distance from the user's present location. Only one of the five participants considered the altitude when selecting a shelter. Thus, many of the participants selected the shelter without considering the possibility of a tsunami. Next, we added a function that displayed the flooded area and conducted further experiments.

\subsection{Summary of the Experiment}

We performed an experiment to evaluate the evacuation support provided by the disaster mode function. The participants were 12 university students, i.e., five were male and seven were female. Nine of the experimental participants had experience of using AkariMap. Thus, three inexperienced subjects participated in the preliminary experiment. We divided the 12 participants into two groups. The members of one group were shown the flooded area on the map screen in the experiment, whereas the other group members were not shown the flooded area. These groups were designated the "displayed group" and "undisplayed group," respectively. We conducted the experiment in an area that was unfamiliar to the participants. We assumed that a disaster had occurred at the experimental site.

The subjects were provided with Android devices. The battery power in the Android terminal at the time the experiment commenced was $30 \%$ and it decreased by $1 \%$ every minute after the experiment started. We aimed to increase the participants' awareness of the battery power levels. After each experiment, we performed a questionnaire-based survey. We determined whether the display of the flooded area affected the selection of the shelter.

\subsection{Selection of the Experimental Site}

Five or more shelters were located around the start point in this experiment. Each participant selected one of the shelters using AkariMap. 
Table 4 shows the details of each shelter. Figure 3 shows the starting point and its spatial relationship with each shelter 4 . The risk levels shown in Table 4 and Figure 3 represent the emergency evacuation site ratings at the time of a tsunami, which were determined by our local government5. There were three levels and a higher level indicated a safer shelter. We did not show participants the emergency evacuation site risk levels during the experiment.

The shelters were ordered in terms of their altitude. Shelter (1) was closest to the starting point, although it was located at a low altitude in a flooded area. Shelter (2) was the second closest to the starting point, although it was located at a low altitude in a flooded area. The start point was selected so that it might be affected by the flooded area. Thus, the emergency evacuation risk levels of Shelter (1) and Shelter (2) were both 1, i.e., they would be at-risk shelters if a tsunami occurred. Shelters (3) and (4) were slightly further from the starting point, but they were located at a high altitude and they were far from the flooded area. Shelter (5) was the furthest from the starting point, but it had the highest altitude and was well away from the flooded area. The emergency evacuation risk levels of Shelters (3), (4), and (5) were 3, which indicated that they would be safe shelters if a tsunami occurred.

\subsection{Experimental Procedure}

We conducted the experiment according to the following procedure.

1. The starting point was unfamiliar to the participants. We assumed that a major earthquake occurred. We asked the participants to select a shelter using AkariMap (in disaster mode).

2. The participants looked at the map screen of AkariMap (disaster mode) and selected their shelter after leaving the start point.

3. The participants arrived at the shelter or ended the experiment after 15 minutes or more. Each participant completed the questionnaire-based survey.

\subsection{Results of the Disaster Mode Function Evaluation}

Table 5 shows the results of the questionnaire-based survey for the disaster mode function experimental evaluation. We used a five-point Likert scale for the evaluation: 1: Strongly disagree, 2: Disagree, 3: Neutral, 4: Agree, and 5: Strongly agree.

Availability of Information about Flooded Areas. Table 6] and Table 7 show the time required to select shelters and the reason for the selections made by the flooded area displayed group and the flooded area undisplayed group, respectively. There was no difference in the time required to make selections

\footnotetext{
${ }^{4}$ We extended the flooded area for the experiment.

${ }^{5}$ http://www.pref . wakayama.lg.jp/prefg/011400/info/index5.html
} 
Table 5. Questionnaire-based survey results based on the experimental evaluation of the disaster mode function (five-point Likert scale)

\begin{tabular}{|c|c|c|c|c|c|c|c|c|}
\hline \multirow[t]{2}{*}{ Question items } & \multirow[t]{2}{*}{ Group } & \multicolumn{5}{|c|}{\begin{tabular}{|l} 
Distribution of \\
evaluation
\end{tabular}} & \multirow[t]{2}{*}{ Median } & \multirow[t]{2}{*}{ Mode } \\
\hline & & \begin{tabular}{|l|l}
1 & \\
\end{tabular} & \begin{tabular}{l|l}
2 & \\
\end{tabular} & 3 & 4 & 5 & & \\
\hline \multirow{2}{*}{$\begin{array}{l}\text { (1) When I selected a shelter using AkariMap, I } \\
\text { considered the possibility that a tsunami might occur. }\end{array}$} & Disp & 0 & 0 & 1 & 1 & 4 & 5 & 5 \\
\hline & Undisp & 1 & 1 & 0 & 1 & 3 & 4.5 & 5 \\
\hline \multirow{2}{*}{$\begin{array}{l}\text { (2) When I searched for a shelter using AkariMap, } \\
\text { I obtained the requisite information. }\end{array}$} & \begin{tabular}{|l|} 
Disp \\
\end{tabular} & 0 & 0 & 0 & 4 & 2 & 4 & 4 \\
\hline & Undisp & 0 & 0 & 0 & 6 & 0 & 4 & 4 \\
\hline \multirow{2}{*}{$\begin{array}{l}\text { (3) When I searched for a shelter using AkariMap, } \\
\text { I identified the shelter immediately. }\end{array}$} & Disp & 0 & 3 & 0 & 0 & 3 & 3.5 & 2,5 \\
\hline & Undisp & 0 & 0 & 2 & 3 & 1 & 4 & 4 \\
\hline $\begin{array}{l}\text { (4) I was conscious of battery power, seeing the screen of } \\
\text { AkariMap. }\end{array}$ & Both & 0 & 3 & 2 & 5 & 2 & 4 & 4 \\
\hline
\end{tabular}

- Disp: displayed group, Undisp: undisplayed group, Both: both displayed and undisplayed groups. - We used a five-point Likert scale for the evaluation: 1: Strongly disagree, 2: Disagree, 3: Neutral, 4: Agree, and 5: Strongly agree.

- The distributions of the evaluation scores were determined for individual subjects.

Table 6. Shelters selected by the flooded area displayed group, the time required to make the selection, and the reason for the selection

\begin{tabular}{|c|c|c|l|}
\hline Participant & Shelter & $\begin{array}{l}\text { Time required to } \\
\text { make the selection }\end{array}$ & Reason for the selection \\
\hline A & (2)Ushimachi Park & About 1 min & $\begin{array}{l}\text { - Flood region or not } \\
\text { - Distance from present location }\end{array}$ \\
\hline B & (3)Onominato Park & About 2 min & $\begin{array}{l}\text { - Distance from flooded area } \\
\text { - Existence of a road }\end{array}$ \\
\hline C & (4)Onominato Elementary School & About 1 min & - Flooded region or not and the altitude \\
\hline D & (3)Onominato Park & About 1 min & $\begin{array}{l}\text { - Distance from flooded area } \\
\text { - Distance from present location }\end{array}$ \\
\hline E & (2)Unimachi Park & Less than 1 min & $\begin{array}{l}\text { - Flooded area or not } \\
\text { - Distance from present location }\end{array}$ \\
\hline F & (4)Onominato Elementary School & About 2 min & $\begin{array}{l}\text { - - Altitude from flooded area } \\
\text { - The shelter was an elementary school }\end{array}$ \\
\hline
\end{tabular}

by the two groups. Table 6 shows that the flooded area displayed group paid particular attention to this information when selecting a shelter. Indeed, none of these participants selected shelters located in a flooded area at the time of the disaster. Table 5 shows that all of the participants in this group were aware of the possibility of a tsunami occurring. Table 7 shows that participants I and $\mathrm{K}$ in the undisplayed group selected Shelter (1), which would have been in the flooded area in the event of a tsunami. These subjects paid no attention to the altitude when selecting a shelter. They were only concerned with the distance from their present location. Moreover, the participants were not aware of the possibility of a tsunami according to Table 5 .

We found that the provision of information about the possible flooded areas made people more aware of the likelihood of a tsunami so they could select a safer shelter. Participants A and E selected Shelter (2), which was not in the flooded area but it was near the flooded area. Thus, Shelter (2) was in an at-risk area in the event of a tsunami and the route to Shelter (2) included flooded areas. Moreover, the subjects traveled to Shelter (2) without avoiding the flooded area in the experiment. This was because participants A and E only considered that the shelter was not located in the flooded area. Thus, they did 
Table 7. Shelters selected by the flooded area undisplayed group, the time required to make the selection, and the reason for the selection

\begin{tabular}{|c|c|c|c|}
\hline Participant & Shelter & $\begin{array}{l}\text { Time required to } \\
\text { make selection }\end{array}$ & Reason for selection \\
\hline $\mathrm{G}$ & (5)Wakayama Park & About $2 \mathrm{~min}$ & $\begin{array}{l}\text { - Altitude } \\
\text { - Distance from present location } \\
\text { - Environment around the shelter }\end{array}$ \\
\hline $\mathrm{H}$ & (4)Onominato Elementary School & About $2 \mathrm{~min}$ & $\begin{array}{l}\text { - Altitude } \\
\text { - Distance from present location }\end{array}$ \\
\hline $\mathrm{I}$ & (1)Tosamachi Park & Less than $1 \mathrm{~min}$ & $\begin{array}{l}\text { - Distance from present location } \\
- \text { Understanding the route }\end{array}$ \\
\hline $\mathrm{J}$ & (4)Onominato Elementary School & About $2 \mathrm{~min}$ & $\begin{array}{l}\text { - Distance from the sea } \\
\text { - Secure shelter and altitude }\end{array}$ \\
\hline $\mathrm{K}$ & (1)Tosamachi Park & About $1 \mathrm{~min}$ & $\begin{array}{l}\text { - Existence of a conspicuous building } \\
\text { - Easily accessible road }\end{array}$ \\
\hline $\mathrm{L}$ & (2) Ushimachi Park & About $1 \mathrm{~min}$ & $\begin{array}{l}\text { - Altitude } \\
\text { - Distance from present location } \\
\text { - Alace I could reach on my own }\end{array}$ \\
\hline
\end{tabular}

not think that it was important that the shelter was at a low altitude and that the route to the shelter might be flooded. Therefore, we consider that it is not sufficient to simply display the altitude of the shelter in the evacuation support system. This is because users might not realize that a shelter at a low altitude could be dangerous to reach if a tsunami occurs. Thus, the route to a shelter and information about the shelter also need to be displayed. Participant $H$ in the undisplayed group also participated in the preliminary experiment. In the preliminary experiment, participant $\mathrm{H}$ selected the nearest shelter to the starting point. In the main experiment, however, participant $\mathrm{H}$ considered the distance and the altitude when selecting a shelter. Participant $\mathrm{H}$ commented that: "The preliminary experiment made me aware of the possibility of a tsunami occurring. Thus, I thought it was important to take the altitude into consideration."

\section{Conclusion}

In this study, we developed an evacuation support system called AkariMap. People can use AkariMap in an offline environment following a disaster and they can also acquire experience of the system in advance by testing AkariMap in disaster mode.

We developed a notification function that encourages users to interact with AkariMap each day. Based on the results of a 30-day experiment and other tests in the disaster mode, we reached the following conclusions.

(1) Subjects increasingly acquired local evacuation support information for about 10 days.

(2) Even if people did not use the notification function in the long-term, they were accustomed to using the system.

(3) Subjects were able to select safer shelters by displaying the possible flooded areas after a tsunami using AkariMap. 
We aim to implement a device to encourage the long-term use of AkariMap. For example, to encourage the continuous use of the system, we aim to develop functions that display information about a random disaster.

Acknowledgment. This work was supported partly by JSPS KAKENHI Grant Number 25242037 and an Original Research Support Project at Wakayama University during 2012-2013.

\section{References}

1. Kazawa, H.: Disaster and the Internet - Lesson learned from the Great East Japan Earthquake (in Japanese), http://www.drs.dpri.kyoto-u.ac.jp/projects/jitsumusha/18/06_kazawa.pdf

2. Steering committee of Great East Japan Earthquake Big data workshop: Great East Japan Earthquake Big data workshop - Project 311 (in Japanese), https://sites.google.com/site/prj311/

3. Saito, H.: Approach situation for the Great East Japan Earthquake in the Ministry of Internal Affairs and Communications, Japan Internet Providers Association (in Japanese), http://www.jaipa.or.jp/IGF-J/2011/110721_soumu.pdf

4. Honjo, S., Yuhashi, H.: An information society strong against a disaster -The Great East Japan Earthquake and mobile communication. NTT publication (2013) (in Japanese)

5. Hamamura, A., Fukushima, T., Yoshino, T., Egusa, N.: Development of Evacuation Support System at the Aftermath of Disaster by Continuous Use in Daily Environment. Proceedings of the 75th National Convention of IPSJ, 4ZF-2, pp. 815-816 (2013) (in Japanese)

6. Fukada, H., Hashimoto, Y., Akabuchi, A., Oki, M., Okuno, Y.: Proposal of Tsunami Evacuation Support System Using a Tablet PC, IPSJ, Multimedia, Distributed, Cooperative, and Mobile Symposium, pp. 1938-1944 (2013) (in Japanese)

7. Hiruta, M., Tsuruoka, Y., Tada, Y.: A proposal of a disaster information sharing system, IEICE Technical Report, MoMuC2012-5, pp. 1-4 (2012) (in Japanese)

8. Fujikawa, M., Kamegawa, M., Matsumoto, Y., Yoshiki, D., Mori, N., Matsuno, H.: Development of a local community system for enhancing the effectiveness of a disaster information system.In: Proceedings of the 74th National Convention of IPSJ, 1E-3, pp. 45-47 (2012) (in Japanese)

9. Hamamura, A., Fukushima, T., Yoshino, T., Egusa, N.: Proposal of Evacuation Support System with Function Training at the Time of Disaster, The Japanese Society for Artificial Intelligence, Special Interest Group on Society and Artificial Intelligence, pp.1-6 (2013) (in Japanese) 